\title{
Time course of end-tidal desflurane concentration during delivery and elimination according to the type and location of filters in a semi- closed circuit system
}

\author{
Sung-Wook Park ${ }^{1}$, Jun-Young Chung ${ }^{2}$, Eun-Jin Moon ${ }^{2}$, Young-Jin Kang ${ }^{1}$, \\ and Jong-Man Kang ${ }^{2}$ \\ Department of Anesthesiology and Pain Medicine, ${ }^{1}$ Kyung Hee University Hospital, ${ }^{2}$ Kyung Hee University Hospital \\ at Gangdong, Seoul, Korea
}

Background: The aim of this study was to determine whether the end-tidal concentration of desflurane would be affected by a breathing circuit system filter attached at two different positions in anesthetic breathing circuit systems. Methods: An artificial lung was ventilated under five different conditions. The first group was without any filter or desflurane $(n=5$, sham), the second was with desflurane but without any filter $(n=10$, control), the third group had a bacterial filter on the expiratory limb $(n=10)$, and the fourth and fifth groups had a viral/bacterial filter added on the expiratory limb $(n=10)$ or at the Y-piece of the breathing circuit $(n=10)$, respectively. In all groups except the sham, administration of $10 \%$ desflurane was performed for 5 minutes and then stopped for 5 minutes.

Results: The mean (SD) end-tidal concentration of desflurane for the groups described above peaked at $0(0), 9.8(0.1), 9.8$ (0.1), $8.5(0.1)$, and 6.7\% (0.1) $(\mathrm{P}<0.001)$, respectively. There was no difference in the desflurane concentrations and the expired tidal volume over time between the control and bacterial group, but there was a significant difference between the control and the fourth and fifth groups $(\mathrm{P}<0.001)$.

Conclusions: Filters can affect the expiratory desflurane concentration during anesthesia.

Key Words: Concentration, Desflurane, Filter, Tidal volume.

Corresponding author: Jong-Man Kang, M.D., Ph.D.

Department of Anesthesiology and Pain Medicine, Kyung Hee University Hospital at Gangdong, 892, Dongnam-ro, Gangdong-gu,

Seoul 134-090, Korea

Tel: 82-2-440-6193, Fax: 82-2-440-7808

E-mail: jongmankang@gmail.com

Received: August 6, 2014.

Revised: 1st, September 11, 2014; 2nd, October 6, 2014.

Accepted: October 6, 2014.

Korean J Anesthesiol 2015 August 68(4): 392-396

http://dx.doi.org/10.4097/kjae.2015.68.4.392

\section{Introduction}

Contamination of the anesthetic machine and breathing circuit system can serve as a source of patient cross-infection. The addition of bacterial or viral filters within the breathing circuit system has been shown to be effective in preventing such infections [1]; however, these filters can induce an error in the analysis and measurement of exhaled gases such as end-tidal $\mathrm{CO}_{2}[2]$.

During mechanical ventilation the piston pump of the ventilator refills with a mixture of fresh gas, gas from the breathing bag, and exhaled gas from the patient [3]. Addition of a filter into the circuit can increase resistance to the gas flow into the

(c) This is an open-access article distributed under the terms of the Creative Commons Attribution Non-Commercial License (http://creativecommons.org/ licenses/by-nc/4.0/), which permits unrestricted non-commercial use, distribution, and reproduction in any medium, provided the original work is properly cited. 


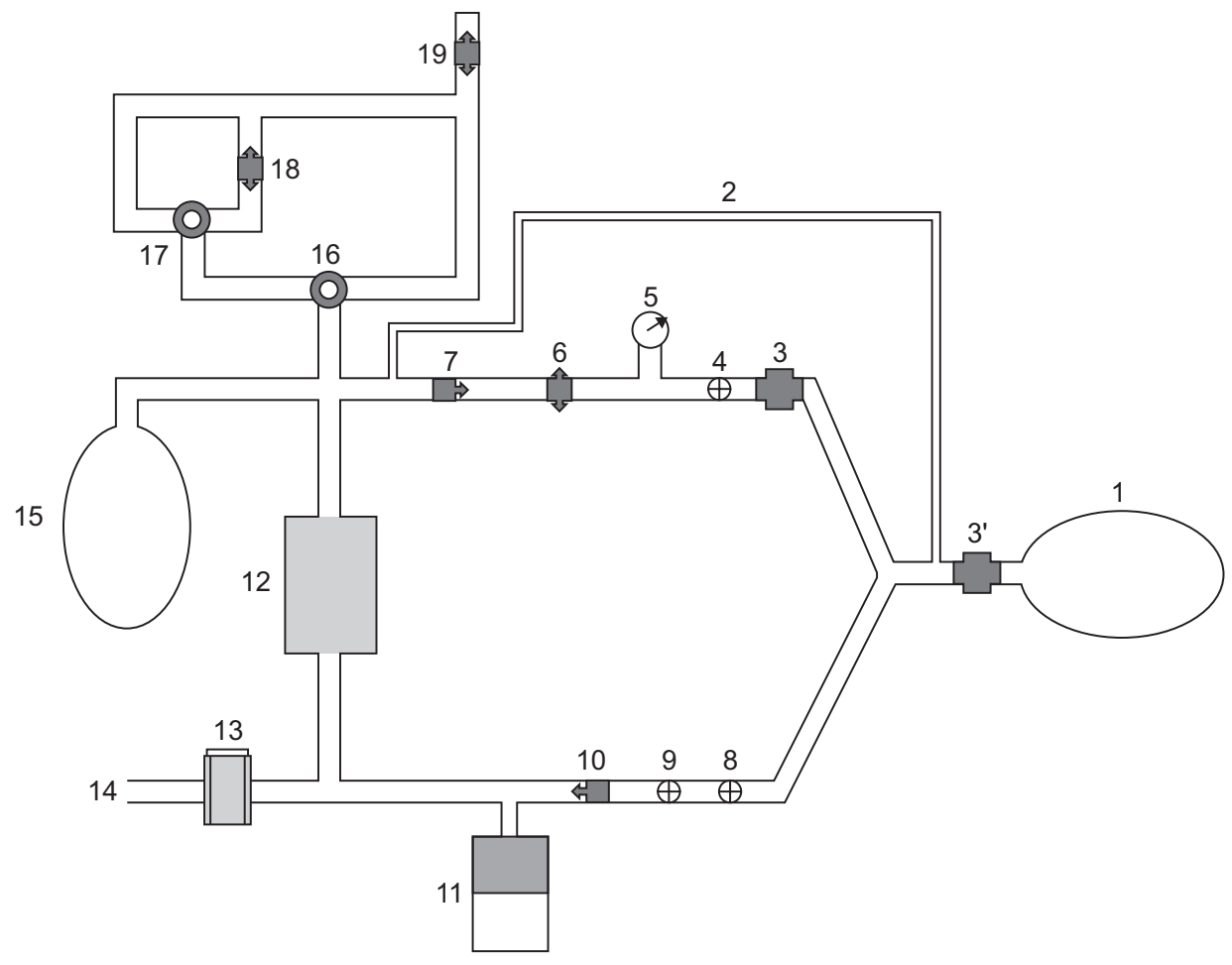

Fig. 1. Schematic view of an artificial semiclosed circuit system with an anesthetic machine (Primus, Dräger Medizintechnik GmbH, Lübeck, Germany). 1: Artificial lung, 2: Sample line, 3 or 3': Filter, 4 : Expiratory flow sensor, 5: Airway pressure guage, 6: Positive end-expiratory pressure/ Pmax valve, 7: Expiratory valve, 8: Inspiratory flow sensor, 9: Peak inspiratory pressure sensor, 10: Inspiratory valve, 11: Ventilator, 12: Soda lime canister, 13: Vaporizer, 14: Fresh gas, 15: Manual ventilation bag, 16: Reversing valve between manual/ mechanical mode, 17: Reversing valve between spontaneous/manual mode, 18: Adjustable pressure limiting valve, 19: Anesthetic gas scavenging system. expiratory valve and the equipment dead space volume, resulting in a compositional change of this gaseous mixture $[4,5]$. Consequently, filters may affect the concentration of inhaled anesthetics during rapidly changing phases such as anesthesia induction or recovery. This in vitro study was conducted to determine whether the end-tidal desflurane concentration changes according to the type or location of filter attached to an artificial semi-closed breathing circuit system.

\section{Materials and Methods}

An artificial lung (5 L reservoir bag) was connected to a breathing circuit system (Fig. 1) of an anesthetic machine (Primus, Dräger Medizintechnik GmbH, Lübeck, Germany) [6]. The study groups had no filter (a sham group with no anesthetic gas $[\mathrm{n}=5]$ and a control group with anesthetic gas $[\mathrm{n}=10])$, a bacterial filter (SF 10C, Ace Medical, Seoul, Korea; $\mathrm{n}=10$ ) or a viral/bacterial filter (MF 10C, Ace Medical; $\mathrm{n}=10$ ) (Fig. 2) added to the expiratory limb of the circuit where the expiratory limb connects with the anesthesia machine, or a viral/bacterial filter added at the Y-piece of the breathing circuit system $(n=10)$. The artificial lung was ventilated with $100 \% \mathrm{O}_{2}$ at a fresh gas flow of $4 \mathrm{~L} / \mathrm{min}$ (tidal volume of $600 \mathrm{ml}$ and respiratory rate of $12 / \mathrm{min}$ ). Desflurane was administered at a vaporizer dial setting of $10 \%$ for 5 minutes and then the dial setting was turned to zero for the next 5 minutes. Desflurane was not administered in the sham group. The inspiratory and expiratory desflurane concentrations

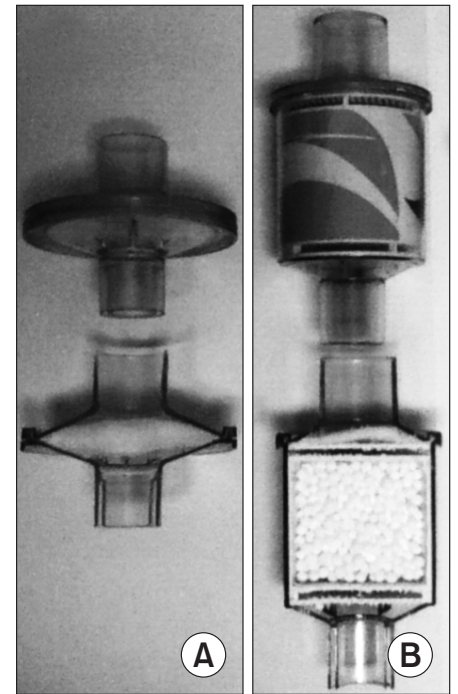

Fig. 2. External and internal (cut) appearance. (A) Bacterial filter (SF 10C, Ace Medical, Seoul, Korea). (B) Viral/bacterial filter (MF 10C, Ace Medical, Seoul, Korea).

were measured at the Y-piece via a side-stream sampling tube and recorded every 30 seconds using the Dräger Infinity Delta Monitor (Dräger Medical AG \& CO, Lübeck, Germany). The exhaled tidal volume and the peak inspiratory airway pressure were also measured.

A pilot study of five bacterial and five viral/bacterial filters of the same type as those used in the main study suggested that a 
sample size of 7 for each group was sufficient for an alpha-error of 0.05 and a power of 0.9 . We therefore decided to test 10 devices in each group.

The end-tidal concentrations of desflurane at 5 minutes in the five groups were compared by one-way ANOVA (SPSS for Windows version 15.0, SPSS Inc., Chicago, IL, USA). The endtidal concentration of desflurane and the exhaled tidal volumes obtained during the 10-minute experiments in all five groups were analyzed by repeat measures ANOVA.

\section{Results}

The recorded desflurane concentration after the first ventilation showed that the inspiratory and expiratory concentrations were the same at every measurement point. However, at 5 minutes after administering desflurane the mean (SD) end-tidal desflurane concentrations peaked at $0 \%(0)$ in the sham group, $9.8 \%$ (0.1) in the control group, 9.8\% (0.1) with the bacterial filter at the expiratory limb, $8.5 \%(0.1)$ with the viral/bacterial filter at the expiratory limb, and $6.7 \%(0.1)$ with the viral/bacterial filter at the Y-piece $(\mathrm{P}<0.001)$. The time course of the mean end-tidal concentration of desflurane and the mean exhaled tidal volume for each group are plotted in Figs. 3 and 4 respectively. There was no difference in the mean end-tidal concentration of desflurane and the mean exhaled tidal volume over time between the control group and the bacterial filter group, but both showed

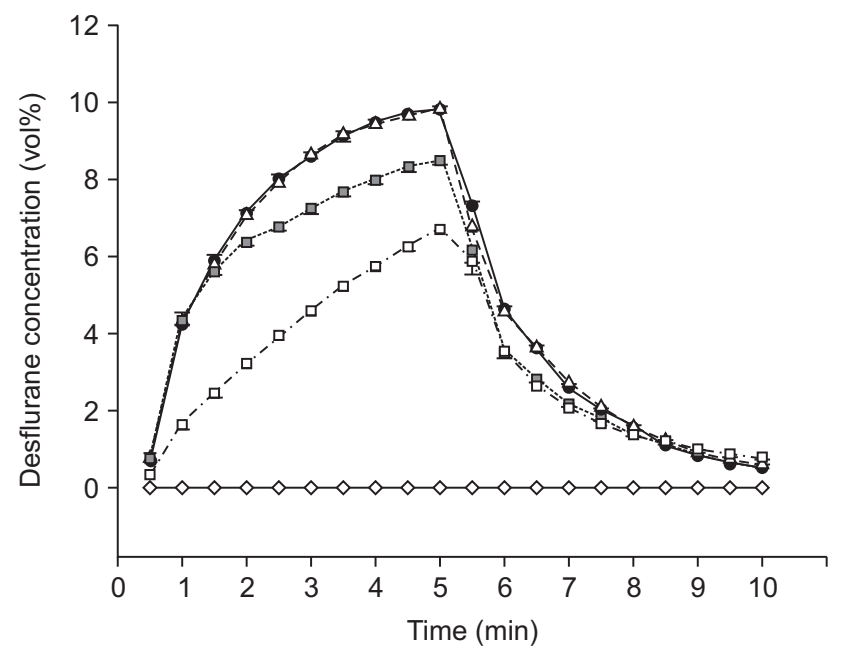

Fig. 3. Time course of the mean end-tidal desflurane concentration for sham group ( $\mathrm{n}=5, \diamond$, solid line), control group ( $\mathrm{n}=10$; $\bigcirc$, solid line), bacterial filter group (SF 10C, Ace Medical, Seoul, Korea; $\mathrm{n}=$ 10; $\triangle$, dotted line), and viral/bacterial filter (MF 10C, Ace Medical) on the expiratory limb $(\mathrm{n}=10$; $\square$, dashed line) or at the Y-piece $(\mathrm{n}=$ 10; $\square$, dot-dashed line). Error bars are SD. There was no difference in the mean expiratory desflurane concentrations over time between the control group and the bacterial filter group, but significant differences were observed for the groups with the viral/bacterial filter $(\mathrm{P}<0.001)$. statistically significant differences between the control and the two groups with viral/bacterial filters ( $\mathrm{P}<0.001$; Figs. 3 and 4 ). Peak inspiratory airway pressures were similar and maintained at $21-23 \mathrm{cmH}_{2} \mathrm{O}$ during the study period irrespective of group except in the group with the viral/bacterial filter group at the Ypiece, which generated pressures between 23 and $25 \mathrm{cmH}_{2} \mathrm{O}$.

\section{Discussion}

Filters can be placed at many sites in breathing circuit systems including the expiratory limb, the inspiratory limb, or both, or between the endotracheal tube and the Y-piece. The use of a single air-flow filter on the expiratory limb of the anesthesia breathing circuit system is standard practice to prevent contamination of the anesthetic machine [7]. The current study demonstrated that addition of a bacterial filter did not influence the end-tidal concentration of desflurane after administration of $10 \%$ desflurane for $5 \mathrm{~min}$, the time course of the end-tidal concentration of desflurane, or the measured tidal volume throughout the study period. In contrast, a viral/bacterial filter significantly affected all of these parameters, with the extent of change depending on the site of attachment.

Viral/bacterial filters are filled with a small bead-like material (Fig. 2) and can be assumed to increase the air-flow resistance in the semi-closed circular system. The viral/bacterial filter used in this study is a type of mechanical filter with a filter media com-

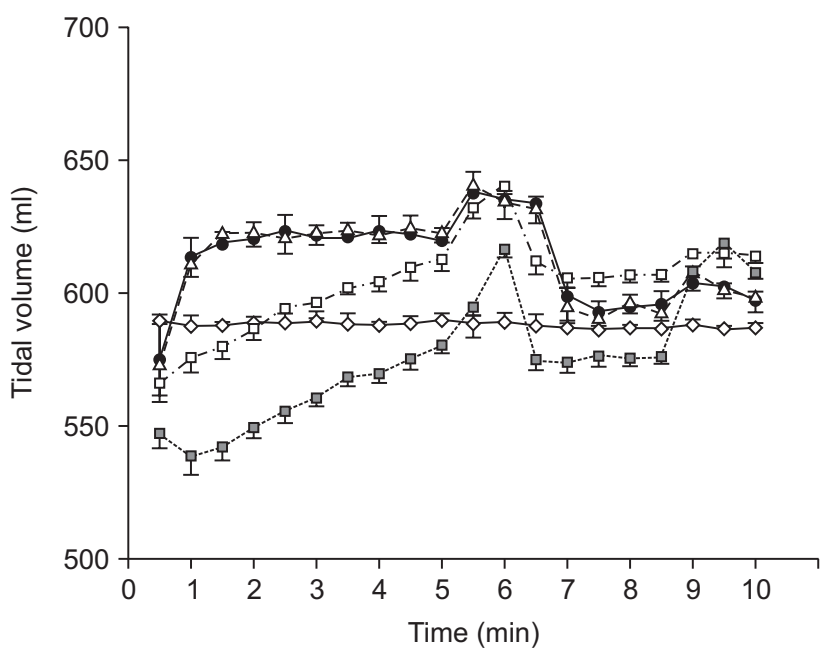

Fig. 4. Time course of the expired tidal volume for sham group ( $n=5 ; \diamond$, solid line), control group ( $\mathrm{n}=10 ; \mathbf{O}$, solid line), bacterial filter group (SF 10C, Ace Medical, Seoul, Korea; $\mathrm{n}=10 ; \triangle$, dotted line), viral/bacterial filter group (MF 10C, Ace Medical) on the expiratory limb ( $n=10$; $\square$, dashed line) or at the Y-piece ( $\mathrm{n}=10 ; \square$, dot-dashed line). Error bars are SD. There was no difference in the mean expired tidal volume over time between the control group and the bacterial filter group, but significant differences were observed for the groups with the viral/ bacterial filter $(\mathrm{P}<0.001)$. 
posed of charged hydrophobic fiber that has electrostatic properties and interrupts the passage of microorganisms. Desflurane (1,2,2,2-tetrafluoroethyl difluoromethyl ether) has a molecular weight of 168. Carbon dioxide and oxygen can pass through these filters but desflurane, which has a larger molecular weight, cannot pass through easily. In addition, some of the desflurane might be absorbed by the filter. Compared with the viral/bacterial filters, bacterial filters may allow larger molecular materials to pass through therefore we expect that the bacterial filter would not absorb desflurane molecules. The results of our study suggest that the viral/bacterial filters partially retain the exhaled gas in the expiratory limb before the filter and decrease the measured exhaled tidal volume compared with the control or bacterial filter group. During the first $5 \mathrm{~min}$ (when the end-tidal desflurane concentration was increasing), the reserved and compressed gas in the expiratory limb that does not pass through the filter may have a relatively low desflurane concentration and is mixed with the next inspiratory gas, which has a higher desflurane concentration than the previous inspiratory stroke. This will happen with every respiratory cycle and will slow down the increase in desflurane concentration compared with the control or bacterial filter groups. In the elimination phase during the last $5 \mathrm{~min}$, opposite effects on the desflurane concentration might be expected. In this study, we presumed that mechanical resistance of the viral/bacterial filters would be the main cause of the relative slowdown in the increase of desflurane concentration; however, we could not exclude the possibility of desflurane adsorption by the filter. Froom et al. [8] reported that the penetration of particles in electrostatic filters of breathing circuit systems increased after exposure to desflurane over time. In other words, exposure to desflurane resulted in a decrease in the filtering capacity. In particular, a significant diminution of the filtering capacity was shown for desflurane among several kinds of volatile agent. Unfortunately these authors could not explain why desflurane has such a significant effect on the breathing circuit filter material.

The measured exhaled tidal volume usually differs from the set tidal volume. The sensor for exhaled volume measurement in a breathing circuit system is located at the expiratory limb adjacent to the expiratory valve and measures exhaled gases plus the gas compressed in the breathing circuit during the previous inspiration. We might expect that some errors in exhaled volume measurements may result from the high inspiratory pressure. When the inspiratory pressure is high, the measured exhaled volume can differ significantly from the actual exhaled volume because of the compliance of the breathing circuit [9]. However, this experiment did not show a large difference between the two volumes as the inspiratory pressures were maintained steadily and the measured exhaled volume was similar to the actual exhaled volume at that inspiratory pressure. Fig. 4 shows that the tidal volumes of the sham group were maintained steadily and did not have the climbing and declining phases that were observed in groups treated with desflurane. The anesthetic vaporizer does not produce immediate equilibration of the inspired gas and set concentration. In the desflurane groups, the desflurane concentration increased gradually in the first half of the study period, as did the expired tidal volume.

The viral/bacterial filter added at the Y-piece may increase the resistance to the inspiratory flow (this is somewhat reflected by maintenance of the peak inspiratory pressures at $23-25 \mathrm{cmH}_{2} \mathrm{O}$ ) and further interrupt the increase in desflurane concentration compared to the filter on the end of the expiratory limb because the the distance between the inspiratory valve and the filter is shortened. As predicted, the graphs of exhaled tidal volume showing the performance of the two groups with the viral/bacterial filter are shifted in parallel along the y axis (Fig. 4).

Our study had several limitations. First, we used filters made by a single company in this research. We might expect that the results of this study would depend to a large extent on the properties of the product used and for more objective results we should perform another study using various kinds of products from other companies. Second, we should include one more group with a bacterial filter added at the Y-piece and compare the data with those of the the group with a viral/bacterial filter added to the Y-piece. This would further show the effect of the type and location of filters. Finally, we should extend the time of the study to observe the increase in end-tidal concentration of desflurane until the expiratory concentration approaches the inspiratory concentration and record the elapsed time. This could be clinically useful information.

Filters attached to the breathing circuit system can affect the end-tidal concentration of inhaled anesthetics, and the current data suggest that this is especially likely during phases of rapid change such as the induction of or recovery from anesthesia. This phenomenon varies according to the type and location of the filter. In this study, a viral/bacterial filter reduced the increase in the end-tidal concentration of inhaled anesthetics whereas a bacterial filter had no significant effect. The time to reach the target concentration of inhaled anesthetics might be much longer than expected if a flow-resistant filter is used. 


\section{References}

1. Hogarth I. Anaesthetic machine and breathing system contamination and the efficacy of bacterial/viral filters. Anaesth Intensive Care 1996; 24: $154-63$.

2. Hardman JG, Mahajan RP, Curran J. The influence of breathing system filters on paediatric capnography. Paediatr Anaesth 1999; 9: 35-8.

3. Gunter JB, Ball J, Than-Win S. Preparation of the Drager Fabius anesthesia machine for the malignant-hyperthermia susceptible patient. Anesth Analg 2008; 107: 1936-45.

4. Mebius C. Heat and moisture exchangers with bacterial filters: a laboratory evaluation. Acta Anaesthesiol Scand 1992; 36 : 572-6.

5. Hedley RM, Allt-Graham J. A comparison of the filtration properties of heat and moisture exchangers. Anaesthesia 1992; 47: 414-20.

6. Chang DJ, Choi SH, Choi YS, Min KT. Effect of charcoal filter on the emergence from sevoflurane anesthesia in a semi-closed rebreathing circuit. Yonsei Med J 2011; 52: 668-72.

7. Smith C, Wygant ME, McGrory R, Silka M. An evaluation of one and two airflow filters in preventing the movement of bacteria through the anesthesia circle system. AANA J 1996; 64: 153-6.

8. Froom SR, Cann C, Wilkes AR, Gildersleve C, Hall JE. The effect of volatile anaesthetic agents on the filtration performance of paediatric breathing system filters. Anaesthesia 2008; 63; 77-81.

9. Bachiller PR, McDonough JM, Feldman JM. Do new anesthesia ventilators deliver small tidal volumes accurately during volume-controlled ventilation? Anesth Analg 2008; 106: 1392-400. 